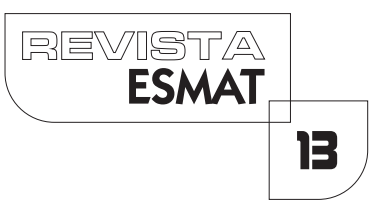

\title{
POLÍTICA BRASILEIRA DE RESÍDUOS SÓLIDOS: REFLEXÕES SOBRE A GERAÇÃO DE RESÍDUOS E SUA GESTÃO NO MUNICÍPIO DE PALMAS-TO
}

BRAZILIAN SOLID WASTE POLICY: REFLECTIONS ON THE GENERATION OF WASTE
AND MANAGEMENT IN THE MUNICIPALITY OF PALMAS-TO

Suyene Monteiro da Rocha

Doutora em Biodiversidade e Biotecnologia - BIONORTE/UFAM. Mestre em Ciências do Ambiente - UFT. Professora Adjunta no curso de Direito da Universidade Federal do Tocantins. Professora no Programa Mestrado Interdisciplinar em Prestação Jurisdicional e Direitos Humanos - UFT. Coordenadora do grupo de pesquisa CNPq: Políticas Públicas Ambientais e Sustentabilidade. E-mail: suyenerocha@uft.edu.br.

Renata Rodrigues de Castro Rocha

Doutora e Mestre em Ciência Florestal pela Universidade Federal de Viçosa - UFV, Minas Gerais. Professora Adjunta do curso de Direito da Universidade Federal do Tocantins - UFT. Professora do Programa Mestrado Interdisciplinar Prestação Jurisdicional e Direitos Humanos UFT. E-mail: renatarocha@uft.edu.br.

Kárita Barros Lustosa

Mestranda - Programa Mestrado Interdisciplinar Prestação Jurisdicional e Direitos Humanos - UFT. Professora do Centro Universitário Unirg, e advogada. E-mail: karytabarros@hotmail.com.

\section{RESUMO}

Nas últimas quatro décadas, governantes têm se reunido com o objetivo de encontrar caminhos para a problemática ambiental, que tem se intensificado. Um dos mecanismos vislumbrados tem sido a edição de políticas públicas que surgem no cenário com o objetivo de mitigar os resultados vividos no presente, fruto do desenvolvimento desordenado de centros urbanos, uso indiscriminado de insumos e sólido. Assim, este trabalho tem como objeto a análise da Lei $n^{\circ}$ 12.305, de 2010 , que instituiu a Política Brasileira de Resíduos Sólidos, sob a perspectiva da gestão de resíduos. A metodologia utilizada neste trabalho centra-se no estudo de exploração excessiva de recursos ambientais. Ante as inúmeras problemáticas que se apresentam no ambiente urbano, o presente trabalho se volta para reflexões acerca da Política Brasileira de Resíduos, que se 
apoiam nas técnicas documental e bibliográfica, evidenciando o seu caráter descritivo. A pesquisa aborda, ainda, a temática Resíduos Sólidos na Região Norte, analisando a geração/coleta de resíduos na Região, no período de 20 I 2-20 I 5, dados esses também que foram coletados e analisados no que se refere ao Município de Palmas-TO, para então verificar a constituição do plano de Gestão de Resíduos Sólidos da referida municipalidade. O resultado do estudo evidencia um Plano em processo de implantação no que concerne à gestão e manejo dos resíduos sólidos no Município de Palmas-TO.

PALAVRAS-CHAVE: Política Brasileira de Resíduos Sólidos; Geração de resíduos; Gestão.

\begin{abstract}
In the last four decades, leaders have met with the goal of finding ways to address environmental issues that have intensified. One of the mechanisms envisioned has been the publication of public policies, which arise in the scenario with the objective of mitigating the results lived in the present, due to the disorderly development of urban centers, indiscriminate use of inputs and excessive exploitation of environmental resources. In view of the numerous problems that arise in the urban environment, the present study focuses on the Brazilian Solid Waste Policy - Law I2305/20 I 0, analyzing Brazilian policy as a driving force in the process of implementing waste management, associated to Federal Constitution of the Federative Republic of Brazil of 1988, National Environmental Policy - Law No. 6.938 / 81, City Statute - Law no. 10.257 / 200. The methodology used in this work focuses on the case study, which relies on documentary and bibliographical techniques evidencing its descriptive character. The research also addresses the issue of Solid Waste in the North Region, analyzing the generation / collection of waste in the Region in the period 20 I 2-20 I 5, data that were also collected and analyzed for the Municipality of Palmas -TO, Study the solid waste management plan of said municipality. The result of the study shows a process under construction regarding the management and management of solid waste in the Municipality of Palmas$\mathrm{TO}$.
\end{abstract}

KEYWORDS: Brazilian Solid Waste Policy; Waste generation; Management.

\title{
I INTRODUÇÃO
}

Direito Ambiental é, por essência, dinâmico, mutante, inovador e integrado, características essas que se materializam em seus princípios, como: desenvolvimento sustentável, direito ao meio ambiente equilibrado, direito à sadia qualidade de vida, direito à participação, ubiquidade, prevenção, reparação, poluidor pagador, informação 
e participação (FIORILLO, 20I I). Apesar de todo o arcabouço principiológico que pode ter tido seu início marcado no ano 1972, com a Conferência de Estocolmo, a realidade social vigente diverge de forma alarmante. Os meios de comunicação divulgam, massificam, aproximam continentes; o "conhecimento" não tem fronteiras na era da tecnologia, e as catástrofes ambientais também não conhecem aquelas. Cotidianamente, têm-se notícias de nevascas como jamais vistas, secas e chuvas torrenciais.

A sociedade do Século XXI tem acesso rápido e dinamismo para o "conhecimento", mas o que se observa é certa relativização do saber, no sentido de fazê-lo efêmero, fast, que determina de forma direta a postura e a presença do indivíduo na sociedade, e seu interesse por temas complexos e controversos, política, economia e meio ambiente. $\bigcirc$ que torna a temática menos atrativa ainda é a inter-relação dos três temas.

Dentre as inúmeras problemáticas ambientais vividas na atualidade, uma que se sobreleva é a do acúmulo de resíduos sólidos. Nunca, em tempos remotos, teve-se notícia de tanto "lixo" ou resíduos sólidos, fato esse gerado a partir do crescimento das cidades e da importância que elas passaram a ter na vida das sociedades.

A população no Planeta Terra, hoje, é essencialmente urbana. A busca de caminhos para a obtenção de qualidade de vida na urbe tem sido o grande desafio não só dos gestores públicos, mas também dos líderes mundiais. Um dos grandes desafios da pósmodernidade é a gestão da cidade sob a perspectiva urbanístico-ambiental. Isso porque o espaço urbano deve propiciar a seus integrantes, com equidade, moradia, lazer, cultura, habitação, mobilidade, educação, segurança, premissas essas insculpidas na Constituição Federal da República Federativa do Brasil, de 1988. Assim, o presente trabalho se debruça sobre as políticas públicas que têm como foco o ambiente urbano, pois compreender tais estruturas permite visualizar o traçado dado não só às ações governamentais, mas também ao desenho que se quer da cidade.

No Brasil, em 20 I0, o governo federal sancionou a Política Nacional de Resíduos Sólidos (PNRS) - Lei n 12.305, de 2010 -, que disciplina seus princípios, objetivos e instrumentos, bem como sobre as diretrizes relativas à gestão integrada e ao gerenciamento de resíduos sólidos, incluindo-se os perigosos, as responsabilidades dos geradores e do poder público e os instrumentos econômicos aplicáveis.

A pesquisa tem foco na referida política, Lei $n^{\circ} 12.305$, de 2010, dada a sua relevância no cenário atual, na busca de compreender a dinâmica operacionalizada pelo legislador à gestão dos resíduos, verificando o papel do cidadão na dinâmica de implementação daquela. Sob esse prisma, como elemento ampliador da visão ora pretendida, a extensão da relevância outorgada ao cidadão no exercício da tutela do meio ambiente será verificada, ainda, sob a égide da Constituição Federal da República Federativa, de 1988, Política Nacional de Meio Ambiente - Lei n ${ }^{\circ}$ 6.938, de 1981 -, Estatuto da Cidade - Lei n ${ }^{\circ} 10.257$, de 2001 -, instrumentos normativos fundamentais para a compreensão exata dessa relação.

Buscou-se, portanto, analisar a Política Brasileira de Resíduos Sólidos vertendo olhar 
para a gestão dos resíduos no município de Palmas-TO, a partir da edição do Decreto $n^{\circ}$ 700, de 2014 (Plano Municipal de Saneamento Básico - Vol. IV), com o fito de verificar a dinâmica empregada pelo administrador público a este tema.

Para implementar o objetivo definido para o estudo, com vista à operacionalização da pesquisa, o plano investigativo está estruturado com base num conjunto de técnicas e instrumentos de coletas de dados compatíveis e complementares entre si, com a finalidade de ampliar a percepção da investigação. A metodologia utilizada neste trabalho centra-se no estudo bibliográfico de caráter descritivo. A pesquisa focaliza-se num prisma qualitativo e não probabilístico, logo, é um processo formal e sistemático de desenvolvimento do método científico. Nesse sentido, possui o presente trabalho algumas especificidades por se caracterizar por um procedimento técnico-bibliográfico, analítico e documental com base empírico-descritiva, sendo objeto direto de estudo a Lei $n^{\circ}$ 12.305, de 2010, que disciplina a Politica Brasileira de Resíduos Sólidos, e o Decreto $n^{\circ} 700$, de 2014.

\section{DAPOLÍTICANACIONALDE RESÍDUOS SÓLIDOS ESUA DIFICIL GESTÃO}

A Política Nacional de Resíduos Sólidos (PNRS) é um arcabouço que congrega um conjunto significativo de normas, leis, práticas e iniciativas locais. Seus 20 anos de tramitação refletem, é claro, a dificuldade de sintetizar orientações gerais e nacionais referentes a uma dimensão tão particular e localizada da vida social.

A gestão dos resíduos obedece a dinâmicas muito diferentes conforme os produtos, as localidades, as possibilidades de sua disposição, de seu reuso ou de sua reciclagem. Além disso, é o poder local que responde por essa gestão, com base em dinâmicas e compromissos específicos. Em tese, pode-se imaginar que a harmonização desse conjunto tão variado de situações e de interesses seria quase impossível.

Na prática, o Brasil passou nos últimos 20 anos pela emergência de sistemas inteligentes e eficientes na solução de problemas que vinham tomando proporções assustadoras, como é o caso do destino das embalagens de agrotóxicos, dos pneus, das baterias automotivas e dos óleos lubrificantes. Otipo de cooperação entre setor privado e setor público, nesses casos, é exemplar, mesmo que haja pontos localizados em que os sistemas ainda devam ser aperfeiçoados.

Esse desempenho nos setores considerados especiais (dados os perigos e a toxidade potencial dos materiais em questão) pode ser visto como conquista do conjunto da sociedade. Está relacionado à formação de um ambiente institucional que, expresso na Política Nacional de Resíduos Sólidos, revoluciona o próprio sentido social da gestão de resíduos sólidos. Até aqui, o que predomina na sociedade brasileira é que se trata de um serviço público, uma obrigação governamental já embutida no conjunto de impostos pagos pelos cidadãos e pelas empresas. A noção de responsabilidade compartilhada rompe com essa cultura institucional. E o que tornou possível essa ruptura foi já se encontrarem disseminados, em legislações e até em decisões judiciais localizadas, os temas mais inovadores da Política Nacional de Resíduos Sólidos. 
O que era considerado "lixo" de forma generalizada em 20 I0, no Brasil obteve uma nova conotação com a edição da Lei $n^{\circ} 12.305$, de $2010^{\prime}$ - Política Nacional de Resíduos Sólidos, sendo seus norteadores a não geração de resíduos, redução, reutilização, reciclagem e tratamento dos resíduos sólidos, bem como disposição final ambientalmente adequada dos rejeitos.

Os onze princípios norteadores da Política Nacional de Resíduos Sólidos estão previstos no art. $6^{\circ}$, dos quais se ressaltam, aqui, a prevenção e a precaução; a visão sistêmica, na gestão dos resíduos sólidos, que considere as variáveis ambiental, social, cultural, econômica, tecnológica e de saúde pública; a ecoeficiência, mediante a compatibilização entre o fornecimento, a preços competitivos, de bens e serviços qualificados que satisfaçam as necessidades humanas e tragam qualidade de vida e a redução do impacto ambiental e do consumo de recursos naturais a um nível, no mínimo, equivalente à capacidade de sustentação estimada do Planeta; a cooperação entre as diferentes esferas do poder público, o setor empresarial e demais segmentos da sociedade; reconhecimento do resíduo sólido reutilizável e reciclável como um bem econômico e de valor social, gerador de trabalho e renda e promotor de cidadania.

Os objetivos da política estão no artigo subsequente e totalizam quinze, dos quais se evidenciam proteção da saúde pública e da qualidade ambiental; não geração, redução, reutilização, reciclagem e tratamento dos resíduos sólidos, bem como disposição final ambientalmente adequada dos rejeitos; estímulo à adoção de padrões sustentáveis de produção e consumo de bens e serviços; adoção, desenvolvimento e aprimoramento de tecnologias limpas como forma de minimizar impactos ambientais; gestão integrada de resíduos sólidos; articulação entre as diferentes esferas do poder público, e destas com o setor empresarial, com vista à cooperação técnica e financeira para a gestão integrada de resíduos sólidos; capacitação técnica continuada na área de resíduos sólidos.

A referida política disciplina, entre outras matérias, a coleta seletiva de resíduos e estabelece como premissa de viabilidade das ações a articulação entre as esferas públicas em seus níveis e a participação direta da sociedade e empresa; a criação de planos de gestão de resíduos sólidos pelos municípios e estados; a logística reversa para as empresas, bem como os planos de gestão de resíduos sólidos para os que se enquadrarem nas previsões.

Na construção de uma nova visão para a gestão dos resíduos, o artigo 25 estabelece a responsabilidade compartilhada: "O poder público, o setor empresarial e a coletividade são responsáveis pela efetividade das ações voltadas para assegurar a observância da Política Nacional de Resíduos Sólidos e das diretrizes e demais determinações estabelecidas nesta Lei e em seu regulamento." Assim, todos devem estar integrados nas ações voltadas à otimização da política.

'Regulamentada pelo Decreto n 7.404 , de 2010. 
A Política Brasileira de Resíduos Sólidos é considerada uma das melhores políticas ambientais e de gestão urbana, traz uma nova mentalidade, propõe estruturas e ações desafiadoras, mas o confronto com a realidade evidencia que em médio e longo prazo dificuldades serão latentes para sua implementação. Há de se verificar uma sinergia entre todos os responsáveis pelo processo, ou seja, o ente público, a empresa e a sociedade.

Sua dinâmica está conectada a cada residência fazendo sua coleta seletiva; às empresas implementando seus planos de gestão; aos gestores públicos fechando lixões e criando aterros, estabelecendo programas e projetos que sejam contínuos, firmando parcerias com cooperativas de coletores de recicláveis. Vislumbra-se a necessidade gritante e pulsante de atividade conjunta, estratégica, direcionada.

Todavia o que se observa é o aumento ano a ano da produção de lixo pela sociedade brasileira, tanto em termos absolutos como per capita. Só no ano de 2015 entre a quantidade de Resíduos Sólidos gerados e o montante coletado foi de "72,5 milhões de toneladas, resulta em um índice de cobertura de coleta de $90,8 \%$ para o país, o que leva a cerca de 7,3 milhões de toneladas de resíduos sem coleta no país e, consequentemente, com destino impróprio". (ABRELPE, 20। 5, p. I8)

Na Região Norte, em 2015, foram geradas 15.745 toneladas/dia de Resíduos Sólidos Urbanos (RSU), destas, 80,6\% foram coletadas. "Dos resíduos coletados na região, 64,2\% ou o equivalente a 8.149 toneladas diárias, ainda são destinados para lixões e aterros controlados". (ABRELPE, 20 I 5, p. 28).

A geração de resíduos sólidos urbanos na Região Norte sofreu um aumento de 2,2\% no período de 2014 para 20 I 5. Conforme Relatório da Abrelpe (20 I 5, p. 29), o quantitativo saltou de 15.4I3 para I 5.745 toneladas/dia. Nesse cenário, importante considerar, do resíduo gerado, terem sido coletadas, em 2014, 12.458, e, em 20। 5, 12.692 toneladas/dia.

Com o fito de ampliar a visão e a perspectiva sobre a gestão dos Resíduos Sólidos Urbanos na Região Norte, realizou-se levantamento de dados referentes ao período de 2012 a 20I5, junto com os relatórios da Abrelpe, e o que se observa é o seguinte panorama:

Tabela I: Resíduos Sólidos Urbanos Gerados e Coletados, no período de 2012 a 20 I5, na Região Norte

\begin{tabular}{|c|c|c|c|c|c|c|c|}
\hline \multicolumn{4}{|c|}{ GERADOS (T/DIA) } & \multicolumn{4}{c|}{ COLETADOS (T/DIA) } \\
\hline 2012 & 2013 & 2014 & 2015 & 2012 & 2013 & 2014 & 2015 \\
\hline 13.754 & 15.169 & 15.413 & 15.745 & 11.585 & 12.478 & 12.458 & 12.692 \\
\hline
\end{tabular}

Fonte: $\operatorname{ABRELPE}(2013,2014,2015)$

Os dados apresentados na tabela I inferem um crescimento constante significativo na geração de Resíduos Sólidos Urbanos; entretanto, o volume de resíduos coletados 
não acompanha essa relação, fato esse que se pode verificar ao contrastar os dados, pois se observa que a quantidade de Resíduos Sólidos Urbanos gerada no período de 4 anos teve um crescimento de 14,47\% na Região Norte; todavia, a coleta no mesmo período obteve um incremento de $9.55 \%$.

Esse é um resultado com equações desastrosas, montanhas de lixo avolumam-se em locais impróprios, contaminando a água e o solo, empesteando o ar e transmitindo doenças. Há de se considerar ainda o potencial desse "lixo" para geração de riqueza e renda, por meio da reutilização e reciclagem. Segundo estimativa do Ipea, a generalização da reciclagem de aço, alumínio, papel (celulose) e vidro geraria $R \$ 8$ bilhões anuais para o sistema econômico, em valores de 2007. No que se refere à reciclagem de alumínio, "[...] em 20 I3, o Brasil reciclou 486 mil toneladas de alumínio, correspondente a 33,7\% do consumo doméstico registrado no período" (ABRELPE, 20। 5, p. 82). Importante considerar que

Brasil também vem mantendo a liderança mundial nas atividades de reciclagem do segmento de latas de alumínio para envase de bebidas; em 2014, atingiu o índice de 98,4\%, que corresponde a 26 I mil toneladas recicladas, seguido pelo Japão com 87,4\% e Estados Unidos com 66,5\%. (ABRELPE, 20 I 5, p. 82)

Em que pese boa posição no que se refere à reciclagem de alumínio, ainda há um longo caminho a ser trilhado para a construção e consolidação da coleta seletiva e reciclagem, no âmbito da gestão administrativa, o que está em jogo, quando se aborda a questão dos resíduos sólidos, é o próprio metabolismo que cada sociedade estabelece com os ecossistemas dos quais depende sua reprodução.

Lixões e baixo aproveitamento de resíduos sólidos exprimem uma relação doentia entre sociedade e natureza. Há uma relação intrínseca com o olhar que a sociedade, como um todo, verte sobre o bem ambiental e não há como se imputar a responsabilidade unilateral ao gestor público. A "gestão" de resíduos sólidos se torna eficaz e eficiente com a formação e estruturação de uma rede, cuja base se encontra na maneira como são concebidos, produzidos, distribuídos, consumidos e descartados os produtos quanto geridos os sistemas de coleta e disposição dos remanescentes do consumo.

Outra ponta deste imbricado problema é o planejamento da oferta de bens e serviços, os agentes econômicos não incorporam os custos sociais da produção de resíduos. Com isso, utilizam mais materiais, energia, recursos bióticos e consomem mais trabalho do que seria necessário caso os impactos do lixo sobre a vida social estivessem contidos nos custos daquilo que oferecem. Ao mesmo tempo, agem como se o destino de seus resíduos fosse um tema externo ao de suas cadeias de valor. Os consumidores, por sua vez, não recebem os sinais nem dispõem de mecanismos eficientes para optar por produtos menos intensivos em materiais, tampouco para 
desempenhar um papel ativo na separação do lixo doméstico, uma das bases centrais do reuso e da reciclagem. O resultado é, globalmente, dramático: do montante total de I tonelada de bens de consumo que os habitantes dos países desenvolvidos consomem por ano, somente I 8\% são recuperados para algum tipo de reciclagem e apenas 2\% para reutilização (ELLEN MACARTHUR FOUNDATION, 20।3).

Nos países, regiões e produtos em que se conseguiu reduzir a quantidade de resíduos, ampliar a coleta seletiva e estimular o reaproveitamento dos materiais, são cada vez mais fortes as evidências de que a gestão contemporânea dos resíduos sólidos é incompatível com a manutenção dos serviços ecossistêmicos dos quais depende a reprodução social.

O que marca de forma decisiva o panorama sobre esse assunto, nos últimos anos, é a consolidação de sistemas em que o setor privado desempenha papel estratégico. $\bigcirc$ que está em jogo não são apenas a saúde pública e a integridade do habitat humano, pois a gestão de resíduos converte-se num dos vetores pelos quais o próprio setor privado obriga-se a reformular seus padrões de oferta de bens e serviços. (ABRAMOVAY, SPERANZA, PETITGAND, 20।3)

\section{GESTÃO DE RESÍDUOS SÓLIDOS NO MUNICÍPIO DE PALMAS-TO}

O estado do Tocantins é o jovem membro da Região Norte, possui 28 anos de existência, com uma estimativa populacional, para 20 I 6, de I.532.902 (IBGE, [s.a.]). A capital do Estado é Palmas, cidade planejada, implantada em 1989, com população atual estimada em 279.856 mil habitantes em 2016.

Antes de adentrar as reflexões relativas à gestão de resíduos sólidos no município de Palmas, importante considerar a gestão de Resíduos Sólidos Urbanos, do estado do Tocantins. Os dados informados pela Abrelpe (20 I3, 20 I 4, 20 I 5), referentes resíduos gerados e coletados no período de 2012 a 20 I 5, estabelecem a seguinte tabela

Tabela 2: Resíduos Sólidos Urbanos Gerados e Coletados, no período de 2012 a 20 I 5, no estado do Tocantins

\begin{tabular}{|c|c|c|c|c|c|c|c|}
\hline \multicolumn{4}{|c|}{ GERADOS (T/DIA) } & \multicolumn{4}{c|}{ COLETADOS (T/DIA) } \\
\hline 2012 & 2013 & 2014 & 2015 & 2012 & 2013 & 2014 & 2015 \\
\hline 1.075 & 1.211 & 1.233 & 1.251 & 927 & 971 & 992 & 1.012 \\
\hline
\end{tabular}

Fonte: $\operatorname{ABRELPE}(2013,2014,2015)$

A Tabela 2 informa que houve crescimento de 16,37\% de resíduos gerados por dia no estado do Tocantins no período de 4 anos, importante ressaltar que o referencial considerado é tonelada/dia. Entretanto, o quantitativo de Resíduos Sólidos Urbanos coletados tonelada/dia obteve um incremento de $9,16 \%$ no mesmo período. O que corrobora a assertiva de que cada vez mais o quantitativo de resíduos que não estão 
obtendo a destinação correta está crescendo, uma vez que a geração de resíduos aumenta a cada ano e a coleta não acompanha o mesmo ritmo.

A Política Nacional de Resíduos Sólidos, no que se refere aos planos de resíduos sólidos, estabelece que estes devem

\begin{abstract}
Abranger o ciclo que se inicia desde a geração do resíduo, com a identificação do ente gerador, até a disposição final ambientalmente adequada dos rejeitos, passando pela responsabilização do setor público, titular ou concessionário, do consumidor, do cidadão e do setor privado na adoção de soluções que minimizem ou ponham fim aos efeitos negativos para a saúde pública e para o meio ambiente em cada fase do "ciclo de vida" dos produtos. (BRASIL, [s.a], [s.p])
\end{abstract}

Com objetivo de cumprir as disposições do artigo 19 da Lei n 12.305 , de 20 10 , o gestor público de Palmas-TO editou, em 20 I 4, o Anexo IV ao Decreto n 700, de I 5 de janeiro (vol. IV - Resíduos Sólidos), no Plano Municipal de Saneamento Básico de Palmas-TO. Importante considerar, ante a amplitude do plano, o objetivo central que é traçado, o de apresentaro

instrumento de gestão, descrevendo a situação atual do município, através do Diagnóstico da situação dos resíduos sólidos gerados, estimando os cenários futuros no Prognóstico que contempla projeções populacionais e de demanda pelos serviços de limpeza urbana e manejo de resíduos sólidos para o horizonte temporal de 30 anos do projeto e, com base nisso, consolidando o planejamento estratégico da gestão dos resíduos, envolvendo a proposição de Programas, Projetos e Ações para cumprir os objetivos e as metas pré-estabelecidas. (PALMAS, 20|4, p. 03)

O referido documento tem uma extensão significativa de 440 páginas, dividas em I 5 elementos, dos quais se apresentam, na Tabela 3, os elementos centrais do documento:

Tabela 3: Estrutura central do Plano Municipal de Saneamento Básico de Palmas-TO - vol. IV Resíduos Sólidos.

\begin{tabular}{|c|l|}
\hline 2 & Caracterização geral do município; \\
\hline 3 & Diagnóstico legal; \\
\hline 4 & Diagnóstico situacional do sistema de limpeza urbana e manejo de resíduos sólidos; \\
\hline 5 & Prognóstico do sistema de limpeza urbana e manejo de resíduos sólidos; \\
\hline 6 & $\begin{array}{l}\text { Prospectivas e diretrizes técnicas para o sistema de limpeza urbana e manejo } \\
\text { de resíduos sólidos; }\end{array}$ \\
\hline
\end{tabular}




\begin{tabular}{|c|l|}
\hline 7 & $\begin{array}{l}\text { Objetivos específicos e metas para o sistema de limpeza urbana e manejo de } \\
\text { resíduos sólidos; }\end{array}$ \\
\hline 8 & Programas, projetos e ações; \\
\hline 9 & Mecanismos para monitoramento e avaliação; \\
\hline 10 & Ações de emergência e contingência; \\
\hline 1 I & $\begin{array}{l}\text { Revisão e atualização do plano municipal de gestão integrada de Resíduos } \\
\text { Sólidos de Palmas-TO. }\end{array}$ \\
\hline
\end{tabular}

Fonte: Elaborado pelos autores a partir das informações coletadas no Plano de Resíduos Sólidos do Município de Palmas-TO

Ao observar a Tabela 3, sobressai-se o item 8, ante o objeto deste estudo, por ter como foco programas, projetos e ações. Ao analisar o documento pode-se verificar a idealização de 9 programas voltados para a gestão de resíduos no município de Palmas, a qual tem por meta

[...] a melhoria do sistema de limpeza urbana e manejo de resíduos sólidos do município, no qual são estabelecidas ações e projetos pré-definidos para o alcance dos objetivos e das metas definidos [...] compatibilizados com o crescimento econômico, a sustentabilidade ambiental e a equidade social no município, conforme evidenciado na Política Nacional de Saneamento Básico (Lei Federal no 1 I.445/2007) e na Política Nacional de Resíduos Sólidos (Lei Federal n 12.305/2010). (PALMAS, 2014, p. 284)

Foram definidos no Plano de Resíduos Sólidos do Município de Palmas-TO os seguintes programas: I. Serviços de Limpeza Urbana e Manejo de Resíduos Sólidos com Qualidade a Todos; 2. Disposição Final Ambientalmente Adequada dos Rejeitos Gerados e Valorização das Atuais Áreas de Disposição Final; 3. Redução, Reutilização e Reciclagem; 4. Participação e Capacitação Técnica de Grupos Interessados; 5. Qualificação, Estruturação e Fortalecimento Institucional e Gerencial; 6. Limpeza Urbana e Manejo de Resíduos Sólidos com Equilíbrio Econômico-Financeiro; 7. Fonte de Negócios, Emprego e Renda; 8. Adequação, Complementação e Convergência do Arcabouço Legal Municipal; 9. Programa Municipal de Educação Ambiental na Gestão e Gerenciamento de Resíduos Sólidos.

Importante ressaltar que cada projeto possui um conjunto de metas, e cada uma destas tem ações e projetos que estão com suas responsabilidades definidas (supervisão, execução, participação, acompanhamento, regulamentação, prioridade e prazo) Nesse sentido, importante pontuar que as metas estabelecidas nos programas devem convergir para a orientação do Ministério do Meio Ambiente (20 I 2, p. 42). 
As metas quantitativas deverão ser fixadas por período, considerando-se como melhor hipótese o lançamento por quadriênios, vinculados aos anos de preparo dos planos plurianuais, e portanto momentos de revisão dos Planos de Gestão. Deverão ser compatibilizadas, principalmente a exigência legal, a capacidade de investimento e a capacidade gerencial.

No município de Palmas, no que se refere à relação de metas para cada programa, o que se observa é a seguinte composição:

Tabela 4: Programas e Metas - Plano Municipal de Saneamento Básico de Palmas-TO - vol. IV Resíduos Sólidos.

\begin{tabular}{|c|c|}
\hline & METAS \\
\hline PROGRAMA I & 14 \\
\hline PROGRAMA 2 & 10 \\
\hline PROGRAMA 3 & 7 \\
\hline PROGRAMA 4 & 4 \\
\hline PROGRAMA 5 & 7 \\
\hline PROGRAMA 6 & 5 \\
\hline PROGRAMA 7 & 1 \\
\hline PROGRAMA 8 & 2 \\
\hline PROGRAMA 9 & 2 \\
\hline
\end{tabular}

Fonte: Elaborado pelos autores a partir das informações coletadas no Plano de Resíduos Sólidos do Município de Palmas-TO

Dentre os programas traçados pelo município de Palmas, importante evidenciar o número 7 que tem como base fonte de negócios, emprego e renda, e possui uma única meta, qual seja,"Implantar ações que favorecem o desenvolvimento de negócio, emprego e renda no município relacionado à gestão de resíduos sólidos" (PALMAS, $20 \mid 4$, p. 3|4). Associada a esta previsão importante considerar que o programa se alicerça na "[...] não geração, redução, reutilização, reciclagem, tratamento e disposição final ambientalmente adequados, bem como reconhecimento do resíduo sólido reutilizável e reciclável como um bem econômico e de valor social, gerador de trabalho e renda e promovedor de cidadania" (PALMAS, 20।4, p. 3 I2), Considerando ainda o potencial econômico e social dos resíduos sólidos.

Há ainda, no Programa 7, o objetivo de "[...] atrair os estabelecimentos privados, voltados à reciclagem, beneficiamento, tratamento e disposição final de resíduos sólidos, a se instalarem no município através de mecanismos para: incentivos fiscais, financeiros e creditícios, cessão de terrenos públicos e instalação de 'Polo de Reciclagem"' (PALMAS, 2014, p. 312). Todavia, essa é uma meta que necessita se materializar. 
O Plano de Resíduos Sólidos do município de Palmas prevê ações para o período de 2014 a 2043. Lógico, pois, que os prazos alocados para cada uma destas não são padronizados, pois consideram as peculiaridades de cada previsão e prioridade.

\section{CONSIDERAÇÕES FINAIS}

Os ditames da Política Brasileira de Resíduos Sólidos alinham-se aos elementos constitutivos principiológicos ambientais, sendo um dos documentos ambientais mais bem-estruturados no ordenamento brasileiro. Todavia, sua efetividade, eficácia e manutenção dependem de uma série de variantes que estão além da própria positivação, como equipe técnica capacitada na gestão municipal, equipe técnicocientífica permanente para implementação das ações da política, participação social para a construção dos programas e projetos, construção de espaço comum para o diálogo, maturidade político-social.

A gestão compartilhada na Política Brasileira de Resíduos Sólidos é um marco singular, por expressar de forma direta e linear que sua efetividade depende da associação do esforço do poder público, do setor empresarial e da coletividade, por serem responsáveis pela efetividade das ações previstas naquela.

A corresponsabilidade na geração, descarte e reaproveitamento dos resíduos é social. A problemática é global. E o fato é que a construção de caminhos mais eficazes e lineares para a efetividade da Política de Resíduos Sólidos perpassa pelo diálogo comum, pela obtenção de um espaço convergente de todos os atores que possibilite o embate e a confronta na busca de ações que possam se materializar em resultados positivos. Mas esse "espaço" precisa ser construído, e, para tal, necessidade do anseio da coletividade, se não toda, uma vez que a totalidade é uma quimera, de parte expressiva dela.

Uma das mais importantes conclusões deste trabalho é que a proximidade e o diálogo com o setor privado, o estabelecimento conjunto de objetivos na gestão de seus resíduos são o melhor caminho para que o tema seja abordado com base em inovação, economia de recursos, racionalidade econômica e eficiência na formação de novos mercados para a reciclagem. A partir do momento em que o setor privado passa a responder pela coleta e destinação, por exemplo, de suas embalagens, o controle sobre a eficiência tem chance de ganhar escala e visibilidade, algo muito distante daquilo que se tem hoje.

É nesse âmbito também que se deve inserir o trabalho dos catadores de materiais recicláveis. A orientação da Política Nacional de Resíduos Sólidos, que os coloca como elementos centrais na recuperação e reciclagem de materiais, é estratégica.

Trata-se agora de saber como será interpretada e institucionalizada. Até aqui tem predominado a ideia de que cabe ao poder público organizar os sistemas de coleta seletiva e neles inserir os catadores, com apoio, é claro, do setor privado e de fundações privadas, muitas vezes. Essa lógica não é consistente com o espírito que rege a ideia de responsabilidade compartilhada. $\bigcirc$ essencial é que as empresas assumam os custos de sistemas capazes de recuperar os materiais remanescentes do consumo daquilo que 
oferecem e na proporção dessa oferta.

No que se refere à gestão de resíduos sólidos no município de Palmas-TO, observase um plano que considerou as múltiplas vertentes que a temática requer; entretanto, não se pode desconsiderar a complexidade de se transporem as barreiras existentes entre a determinação estabelecida no plano à sua materialização na vida cotidiana da cidade, pois a composição de programas e de ações, com a finalidade de se atender a diversas temáticas que a gestão de resíduos sólidos demanda, requer um diálogo inter e multisetorial no qual a sociedade esteja e seja ator vibrante, uma vez que a dinâmica da gestão de resíduos requer uma nova etapa de modelamento de políticas públicas que desconstrói o paternalismo estatal e almeja o recrutamento de envolvidos para que a conjugação de esforços supere a aliança entre tributação e providência estatal, caracterizada pela conduta social que entrega ao poder estabelecido suas mazelas e implora por soluções que moram na casa ao lado.

\section{REFERÊNCIAS}

ABRAMOVAY, Ricardo. Lixo zero: gestão de resíduos sólidos para uma sociedade mais próspera / Ricardo Abramovay, Juliana Simões Speranza, Cécile Petitgand. - São Paulo : Planeta sustentável : Instituto Ethos, 2013. Disponível em: < http://ricardoabramovay.com/wp-content/uploads/20 / 4/I//LixoZero_ebook_iba.pdf >. Acesso em 24 abr. 2017.

ABRELPE. Panorama dos Resíduos sólidos no Brasil 2015. Disponível em: $<$ http://www.abrelpe.org.br/panorama_envio.cfm?ano=anexos20I 5 > . Acesso em: 20 abr. 2017

- Panorama dos Resíduos sólidos no Brasil 2014. Disponível em: <http://www.abrelpe.org.br/Panorama/panorama20l4.pdf >. Acesso em 20 abr. 2017

- Panorama dos Resíduos sólidos no Brasil 2013. Disponível em: <http://www.abrelpe.org.br/Panorama/panorama2013.pdf >. Acesso em 20 abr. 2017

ARNSTEIN, S. R. A ladder of citizen participation. Journal of the American Planning Association, v. 35, n. 4, p. 216-224, July 1969.

BRASIL. Constituição da República Federativa do Brasil de 1988. Disponível em:

<http://www.planalto.gov.br/ccivil_03/constituicao/constituicao.htm>. Acesso em: 12 fev. 2017.

. Lei 10.257 de 10 de Julho de 200 I. Estatuto da Cidade . Disponível em:< http://www.planalto.gov.br/ccivil_03/leis/leis_200I/l I0257.htm >. Acesso 5 fev. 2017 
.Lei 12.305 de 02 de agosto de 20 10. Política Nacional de Resíduos Sólidos Disponível em:< http://www.planalto.gov.br/ccivil_03/_ato20072010/20 I0/lei/l 2305.htm > . Acesso em I ${ }^{\circ}$ fev.2017

MINISTÉRIO DO MEIO AMBIENTE. Disponível em:<http://www.mmma.gov.br> . Acesso em 5 fev.2017

. Planos municipais de gestão integrada de resíduos sólidos. Disponível em: $\overline{<h t t p: / / w w w . m m a . g o v . b r / c i d a d e s-s u s t e n t a v e i s / r e s i d u o s-s o l i d o s / i n s t r u m e n t o s-d a-~}$ politica-de-residuos/planos-municipais-de-gest\%C3\%A3o-integrada-deres\%C3\%ADduos-s\%C3\%B3lidos>. Acesso em II maio 2017.

CARVALHO, M. C. A. A. Participação social no Brasil hoje. 1998. Disponível em http://polis.org.br/publicacoes/participacao-social-no-brasil-hoje/. Acesso em 28 set. 2016.

CUNILL, N. Participación ciudadana. Dilemas y perspectivas para la democratización de los Estados Latinoamericanos. Caracas: Clad, I99I.

FIORILLO, Celso Antônio Pacheco. Curso de Direito Ambiental Brasileiro. São Paulo: Saraiva, 2011 .

JACOBI, P. Descentralização municipal e participação dos cidadãos: apontamentos para o debate. Revista Lua Nova, n. 20, p. I 2 I - |43, maio 1990.

MANFREDINI, C.; LOPES, J. R. Participação comunitária em projetos de desenvolvimento local: um estudo no bairro de Marins, Piquete/SP. In: ENCONTRO ANUAL DAANPAD, 29., Brasília, 2005. Anais. Brasília: Anpad, 2005.

MEDEIROS; Jássio Pereira de; BORGES, Djalma Freire. Participação cidadã no planejamento das ações da Emater-RN. Disponível em $<$ http://www.scielo.br/scielo.php?script=sci_arttext\&pid=S003476 122007000|00005>. Acesso em lo ago. 2017.

PALMAS. Decreto n 700 de 15 de janeiro de 20।4. Plano Municipal de Saneamento Básico de Palmas - TO (vol. IV - Resíduos Sólidos). Disponível em: <http://www.palmas.to.gov.br/media/doc/arquivoservico/PMSB_Palmas_Volume_04 _Residuos_Solidos_Versao_Final.pdf $>$. Acesso em 5 março 2017.

Recebido em: 07/06/2017

Aprovado em: 14/06/20 17 